\title{
Environmental benefit analysis of power transmission project based on analytic hierarchy process
}

\author{
Kang Yanfang ${ }^{1,}$, Guo Xinju ${ }^{1}$, Li Dapeng ${ }^{1}$, Li Xuyang ${ }^{1}$, Zhang Yifan ${ }^{2}$ \\ ${ }^{1}$ State Grid Henan Electric Power Economic Technology Research Institute, Zhengzhou 450000, \\ China \\ ${ }^{2}$ State Grid Kaifeng Electric Power Economic Technology Research Institute, Kaifeng 475000, \\ China \\ *Corresponding author: Kang Yanfang \\ E-mail: 154626491@qq.com
}

Keywords: Power transmission project, Environmental benefit, Analytic Hierarchy Process

\begin{abstract}
The impact of different power transmission projects on the environment of the atmosphere, water, noise, etc. It is important to evaluate environmental benefits scientifically and objectively. Evaluate results is for ensuring long-term stability of power transmission projects. This paper puts forward the screening method and decision analysis about the influencing factors of environmental benefits of power transmission project though the analytic hierarchy process (AHP). This paper constructs the index system of environmental impact of power transmission project. We get the weight of environmental benefits about different indicators of power transmission projects, through the surveys. Then we construct the environmental benefit evaluation model of power transmission projects. And we decide the factors which has a greater impacts on environmental benefits. At last we raise the corresponding policy to solute the environmental problems, which arise from the future power transmission projects' construction.
\end{abstract}

\section{Introduction}

The state will be the basic construction of power transmission projects as the key energy projects. While considering the profitability of power transmission engineering, it should also take into account its social. The power transmission engineering is a public infrastructure closely related to public life. In recent years, Demand for power in China has been increasing with urbanization. At the same time, environmental problems are becoming more and more prominent, such as the increasing number of environmental complaints from the construction of power transmission projects. In addition, there are some pre-construction problems of the power transmission projects, which will influence the construction on schedule, and so on. These problems are the widespread attention of the society. When we study the environment problem, we should divide the problem into construction and operation. At last, we determine the prominent environment factors of power transmission project during construction and operation. In order to guide the future environmental protection of power transmission project, we put forward to some suggestion.

Relate to environmental impact of power transmission project construction, Morozow [1] chose 
the project plan based on environmental benefit. Barros [2] uses the environmental advantage index to construct pareto optimal function. In view of the unreliability cost of extending power transmission capacity, the transmission project is sorted by the environmental benefit selected. Attaviriyanupap [3] analysis the cost benefit of power transmission project, considering the factors of social welfare, we set up the environmental cost efficiency measurement framework, and put forward the corresponding suggestions. Zheng [4] proposed the economic evaluation method of power transmission project to solve the problem about economic benefit of power transmission expansion and the fair distribution income of power transmission project. Pu wenqing [5] research the relationship between the electromagnetic environment impact assessment, ecological environment impact assessment and noise environmental impact assessment.

For the special complexity of power transmission project, which is constructed and is running, we put forward the environment benefit evaluation model of the power transmission project,based on analytic hierarchy process (AHP), accord to the content of the environmental benefits of factor analysis in this paper. We set up a corresponding evaluation index system of environmental benefits. We take advantage of AHP to determine the weight of each environmental influencing factor and the membership of each index factor. Finally we choose factors that affected the environmental benefits of power transmission project mostly.

\section{Analytic Hierarchy Process}

\subsection{Establish a hierarchical model}

We decompose the ultimate goal into plan layer, guideline layer, and target layer. The highest level is the environmental benefit for the major power transmission project. The lowest level is the influencing factor level, which is the environmental impact factor that affects the major power transmission project.

\subsection{Construct Judgment Matrix}

Starting from the second level, we construct the two comparison judgment matrix until the last layer.

$$
A=\left(a_{i j}\right)_{n \times n}, a_{i j}>0, a_{i j}=\frac{1}{a_{j i}}(i, j=1,2, \ldots, n)
$$

.In the judgment matrix $\mathrm{A}, a_{i j}$ is the importance ratio

between factor $\mathrm{i}$ and factor $\mathrm{j}$ to the of the previous level factor. ${ }^{a_{i j}}$ is the importance ratio of factor $\mathrm{j}$ to factor i. $a_{i j}=\frac{1}{a_{j i}}$. For values $a_{i j}$, we usually assign a value of 1 to 9 , and its bottom as the scale. In this paper, we set the judgment matrix of the environmental benefit about the major power transmission project. We select nine experts to evaluate the importance of element $\mathrm{j}$ to the element $\mathrm{i}$.

\subsection{Calculate eigenvalues and eigenvectors of the judgment matrix $B$, and make its consistency check.}

For $\mathrm{B}$, we calculate eigenvalues and eigenvectors of $\mathrm{B}$, that is to calculate eigenvalues and eigenvectors satisfied $^{B \alpha=\lambda_{\max } \alpha}, \lambda_{\max }$ is maximum characteristic root. $\alpha$ is the unit eigenvector of $\lambda_{\max }$. $\alpha$ is the relative weights that compared element to the element. And then we go to the hierarchy order. Since the judgment experts have different judgment results, it is necessary to check the consistency of the judgment matrix. 


\subsection{Decisions Based on Hierarchy}

According to the above steps, we can get weight vector about a set of elements to its upper elements. In turn, we sort merge according to the layer weights. As a result, we get the weight sorting that the element of each scheme at the end layer to the target layer element. At last, we calculate the total order to the scheme layer, and select the optimal solution.

\section{Model determination}

\subsection{Set hierarchical structure model}

Firstly, the environmental benefit of the power transmission project is the decision objective, and the problem is solved as the highest level of the model, which is the overall goal of the analytic hierarchy process. The goal of decision is to find the most influential factors for environmental benefit. There are many factors that affect the environmental benefit of power transmission project. It is the multi-objective decision that combined quantitative environment factors with qualitative environment factors together.

Then, we determine the middle layer that is influence factors of the quasi-lateral layer. In order to set goals, we should find the most factors that influence the power transmission project. We summed up research literature about the environmental at present, this paper mainly consider the ecological environment factor , the living environment factor, the resources and environment cost factor, the noise pollution factor, electrical energy alternative factor, when to determine the environmental affecting factors. These five factors are the influence factors of the quasi-lateral layer. For different power transmission projects, we decide the factors of the middle layer, according to the characteristics of the projects itself, so as to decide the factors impacted the project mostly.

Finally, we decide the bottom factors. This layer is the alternative scheme layer, which represents various factors that affect environmental benefit.

In this paper, 100 power transmission projects were selected as sample data, and the environmental benefit factors were investigated. The results of its investigation are shown in figure 1:

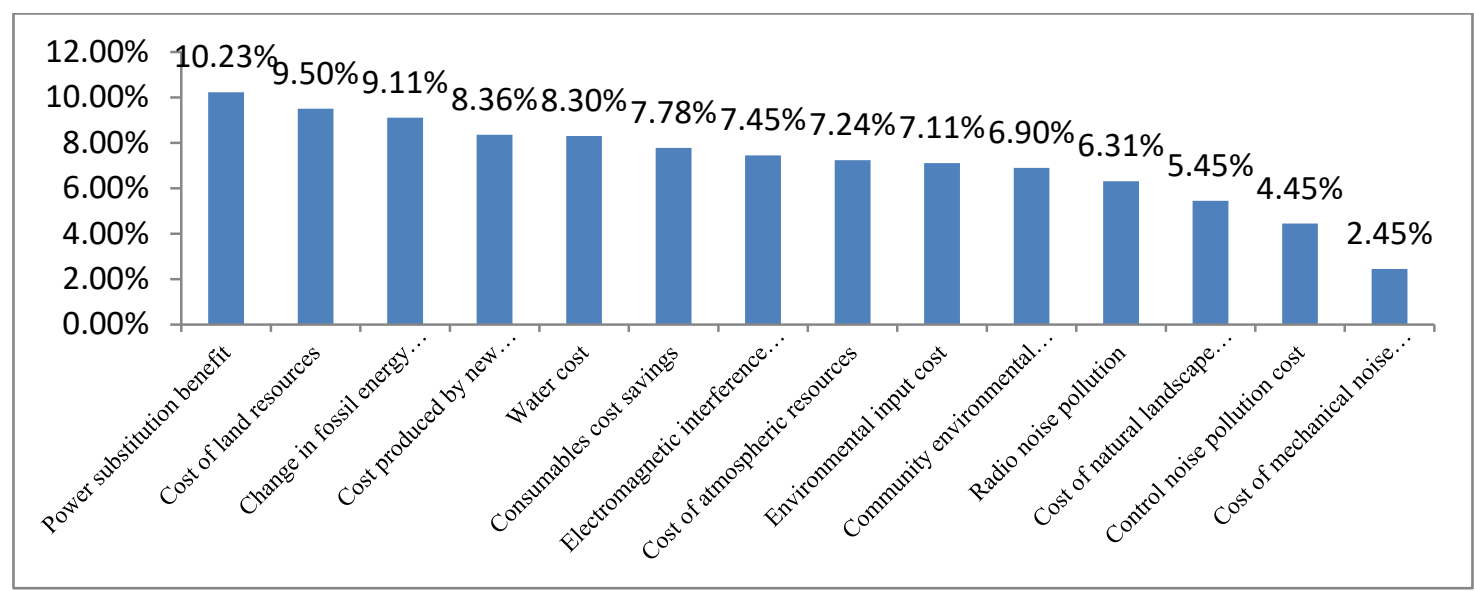

Fig 1 Investigation on environmental benefit factors of transmission and transformation projects.

We can be seen from the figure 1 that the environment problems produced by power transmission projects include the continuous audible noise, power frequency magnetic field and electric field, radio interference during the operation period. For example, the impact of the project on the environment in the construction period is mainly in the aspects of land occupation, relocation, soil erosion and ecological. Among them, the main performance is via the residential buildings on 
both sides of the road, which may lead to the relocation of residents and the removal of relocation problems. The land covered and temporary construction land will affect the production of crops to some extent. The establishment of the transmission line corridor and the space of the tower will affect the functional use of the surrounding land, the plant and the wild environment of the project. Therefore, the 11 factors influenced are selected as the alternative plan layer.

To sum up, we get the structural diagram of the environmental impact factors about the power transmission projects, as shown in Fig. 2. Multilevel index evaluation system of environmental benefits can be seen from the Fig. 2.Among them there are five secondary index, that is ecological environment, living environment, resources and environment cost, noise pollution, energy substitution cost. There are ten third indicators index that is water resources cost, atmospheric resources cost, land resources cost, community environmental treatment cost, the noise pollution of the electromagnetic interference, the radio noise pollution, etc.

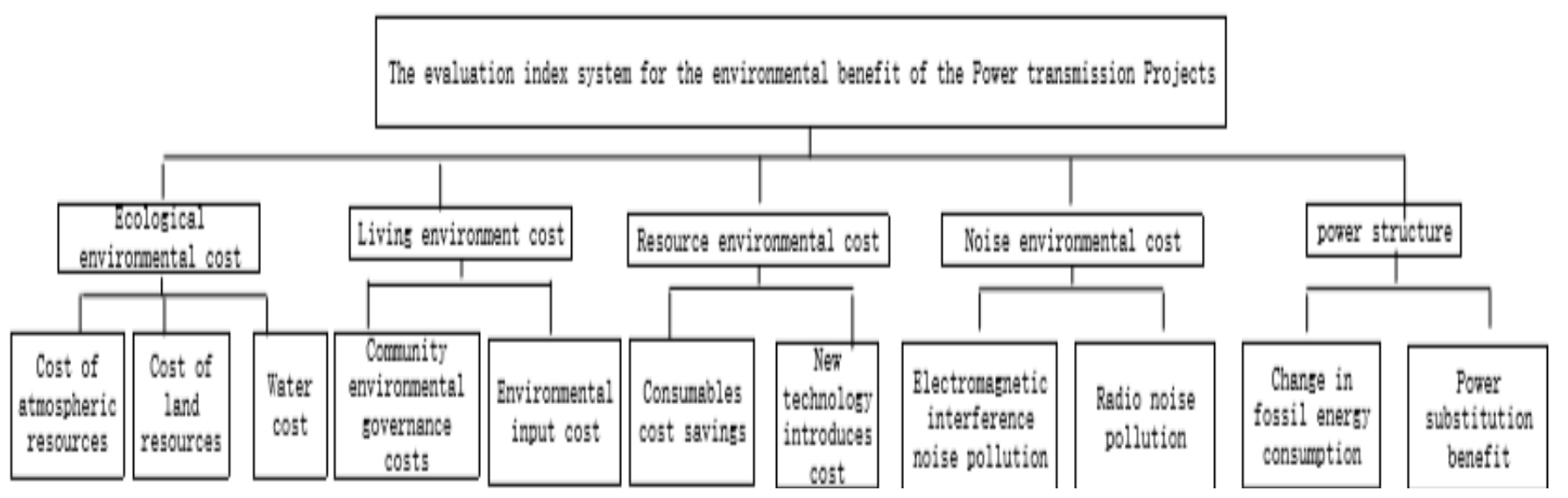

Fig. 2 AHP model of environmental benefit factors of power transmission projects

\subsection{Weight determination and test of all levels factors}

To construct judgment matrix and determine the relative weight is a process of qualitative and quantitative. First of all, the importance of each layer should be compared with that of the previous layer. The judgment matrix is constructed by using Saaty's scale of 1 to 9. When we set decision structure model about environmental factors of the power transmission projects, we should consider different size of power transmission projects, different construction environment, different running environment and so on. Judgment matrix should be judged according to the situation.

Secondly, the consistency test of the constructed judgment matrix is carried out. When $\mathrm{CI}=0$, perfect agreement. The greater the CI value, the worse the consistency of judgment matrix is. Generally, as long as $C I \leq 0.1$, the consistency of judgment matrix is acceptable. If $\mathrm{CI}>0.1$, the relative weight value of the judgment matrix should be adjusted, until $C I \leq 0.1$.

According to above steps, we adopt Yaahp software to deal with. First of all, open the Yaahp software, For every factor in the three layers establish a hierarchy as shown in figure 2. Secondly, we set structure comparative judgment matrix. Because aij=1/aij, we just need to input aij. Such as the first line of the second column represents the factors influenced the environmental benefits of power transmission projects. In which the importance of the ecological environment cost and the living environment cost is 3. That is to say the former is more important than the latter. And so on and so forth. After completing the values required by the table, the system will automatically conduct the consistency check of the matrix. If CI $>0.1$, we need to reset the judgment matrix until it is done.

In order to decide the most influential factors of power transmission projects for the 
environmental benefits target is the compare consistency of judgement matrix, $\mathrm{CI}=0.0431$. The weight of the total target is 1 . Characteristic root $\lambda_{\max }=5.0312$, The corresponding eigenvectors after normalization is: $(0.2442,0.2031,0.2965,0.1106,0.1456)$. See table 1

Table 1 Judgment matrix of criterion layer on target layer

\begin{tabular}{|c|c|c|c|c|c|c|}
\hline & $\begin{array}{l}\text { Ecological } \\
\text { environmental co }\end{array}$ & $\begin{array}{l}\text { Living } \\
\text { environment } \\
\text { cost }\end{array}$ & $\begin{array}{l}\text { Resource and } \\
\text { environmental } \\
\text { costs }\end{array}$ & $\begin{array}{l}\text { Noise } \\
\text { environmental cost }\end{array}$ & $\begin{array}{l}\text { The power } \\
\text { structure }\end{array}$ & $\omega_{\mathrm{i}}$ \\
\hline $\begin{array}{l}\text { Ecological environmental } \\
\text { cost }\end{array}$ & 1 & 3 & 4 & 2 & 3 & 0.2442 \\
\hline Living environment cost & $1 / 3$ & 1 & 4 & 3 & 7 & 0.2031 \\
\hline $\begin{array}{l}\text { Resource and environmental } \\
\text { costs }\end{array}$ & $1 / 4$ & $1 / 4$ & 1 & 2 & 4 & 0.2965 \\
\hline Noise environmental cost & $1 / 2$ & $1 / 3$ & $1 / 2$ & 1 & 5 & 0.1106 \\
\hline The power structure & $1 / 3$ & $1 / 7$ & $1 / 4$ & $1 / 5$ & 1 & 0.1456 \\
\hline
\end{tabular}

Thirdly, the judgment matrix of each factor relative to the middle layer is listed.

Ecological environment of paired comparison judgment matrix consistency index CI $=0.0634$, the total weight target is 0.2442 , characteristic root $\lambda_{\max }=4.8907$. After standardization, the characteristic vector $\omega_{\mathrm{i}}$ is: $(0.3942,0.3423,0.2635)$. See table 2 :

Table 2 Ecological environment cost evaluation matrix

\begin{tabular}{lllll}
\hline $\begin{array}{l}\text { Ecological } \\
\text { environmental cost }\end{array}$ & $\begin{array}{l}\text { Air resources } \\
\text { Cost }\end{array}$ & Water cost & Land resources Cost & $\omega_{\mathrm{i}}$ \\
\hline Air resources Cost & 1 & 1 & 3 & 0.3942 \\
Water cost & 1 & 1 & 4 & 0.3423 \\
Land resources Cost & $1 / 3$ & $1 / 4$ & 1 & 0.2635 \\
\hline
\end{tabular}

Living environment cost of paired comparison judgment matrix consistency index CI $=0.0431$, the total weight target is 0.2031 . the characteristic root $\lambda_{\max }=2$, the corresponding eigenvectors after normalization $\omega_{\mathrm{i}}$ is :(0.5, 0.5). As shown in table 3.

Table 3 Living environment cost evaluation matrix

\begin{tabular}{llll}
\hline Living environment cost & $\begin{array}{l}\text { Community environmental } \\
\text { governance cost }\end{array}$ & $\begin{array}{l}\text { Environmental input } \\
\text { cost }\end{array}$ & $\omega_{\mathrm{i}}$ \\
\hline Community environmental & 1 & 1 & 0.5 \\
governance cost & 1 & 1 & 0.5 \\
Environmental input cost & 1 & 1 & 0.5 \\
\hline
\end{tabular}

Resources and environment cost of paired comparison judgment matrix consistency index $\mathrm{CI}=0.0536$, the total weight target is 0.2965 . the characteristic root $\lambda_{\max }=5.9010$, the corresponding eigenvector after normalization $\omega_{\mathrm{i}}$ is $(0.2477,0.7523)$. As shown in table 4. 
Table 4 Resource environment cost evaluation matrix.

\begin{tabular}{|c|c|c|c|}
\hline Resource and environmental costs & $\begin{array}{c}\text { Consumables } \\
\text { cost save }\end{array}$ & $\begin{array}{c}\text { New technology } \\
\text { introduces cost }\end{array}$ & $\omega_{\mathrm{i}}$ \\
\hline Consumables cost save & 1 & $1 / 3$ & 0.2477 \\
\hline New technology introduces cost & 3 & 1 & 0.7523 \\
\hline \multicolumn{4}{|c|}{$\begin{array}{l}\text { Noise environmental cost of paired comparison judgment matrix consistency index CI=0.0724, } \\
\text { the total weight target is } 0.1106 \text {, the characteristic root } \lambda_{\max }=6.0910 \text {, the corresponding eigenvector } \\
\text { after normalization } \omega_{\mathrm{i}} \text { is }(0.7980,0.2020) \text {. } \\
\text { Power structure cost of paired comparison judgment matrix consistency index CI=0.0692, the } \\
\text { total weight target is } 0.1456 \text {, the characteristic root } \lambda_{\max }=5.3891 \text {, the corresponding eigenvector after } \\
\text { normalization } \omega_{\mathrm{i}} \text { is }(0.1770,0.8230) \text {. As shown in table } 5 \text {. } \\
\text { Table } 5 \text { power structure evaluation matrix }\end{array}$} \\
\hline Power structure & $\begin{array}{c}\text { Change in fossil energy } \\
\text { consumption }\end{array}$ & $\begin{array}{c}\text { Power substitution } \\
\text { benefit }\end{array}$ & $\omega_{\mathrm{i}}$ \\
\hline $\begin{array}{l}\text { Change in fossil energy } \\
\text { consumption }\end{array}$ & 1 & $1 / 5$ & 0.1770 \\
\hline Power substitution benefit & 5 & 1 & 0.8230 \\
\hline
\end{tabular}

\subsection{Environmental benefit evaluation and analysis}

Finally we calculate the various factors that influenced the environmental indicators of power transmission projects in weight. And then on the basis of calculation results to choose the biggest factor on the environmental benefit see table 6 for details. We can be seen from the figure 3, the influence factors of environmental an benefit, that accounted for a significant, is new technology import cost, alternative energy efficiency, environmental protection, and community environment management cost. Therefore, these four factors have the greatest impact on environmental benefits.

We can be seen from the above analysis results, for the most of the power transmission projects to improve its environmental benefits during construction and operation, should be from the new technology introduction, alternative energy, environmental protection, and community environmental governance. Investment effect from above is more obvious. The introduction of new technology mainly relies on the new technology to improve the construction of power transmission project and the existing construction technology during operation. It can greatly save land and corridor, to reduce soil erosion and cut down trees, so as to ensure the environment. Improve work efficiency. Increase transmission capacity of power grid. In electrical energy alternative, we promote actively electric energy replacement project to implement. Minimize the use of fired coal and fuel largely, so as to achieve the goal of improving the urban air quality. Environmental protection investment and community environmental governance mainly adopt the low noise equipment, and adopt noise reduction measures to prevent the noise from disturbing the people. After treatment, the sewage sludge can be used to spray the road and the greening in the station area. The transformer waste liquid produced should be properly treated to prevent the recontamination. Project through the forest, we should take the measures such as tower type, tower span, span increases, to reduce the occupancy and deforestation, to prevent the destruction of ecological environment and landscape. 
Table 6 Weight calculation process about environmental benefit factors of power transmission projects

\begin{tabular}{ll}
\hline Index factors & weight \\
\hline Air resources Cost & $0.2442 \times 0.3942=0.096$ \\
Water cost & $0.2442 \times 0.3423=0.073$ \\
Land resources Cost & $0.2635 \times 0.2442=0.064$ \\
Community environmental governance cost. & $0.2031 \times 0.5=0.1016$ \\
Environmental input cost & $0.2031 \times 0.5=0.1016$ \\
Consumables cost savings & $0.2477 \times 0.2965=0.073$ \\
New technology introduces cost & $0.2965 \times 0.7523=0.2230$ \\
Electromagnetic noise interferes pollution & $0.1106 \times 0.7980=0.0882$ \\
Radio noise interferes pollution & $0.2020 \times 0.1106=0.0236$ \\
Change in fossil energy consumption. & $0.1770 \times 0.1456=0.0257$ \\
Power substitution benefit & $0.8230 \times 0.1456=0.1198$ \\
\hline
\end{tabular}

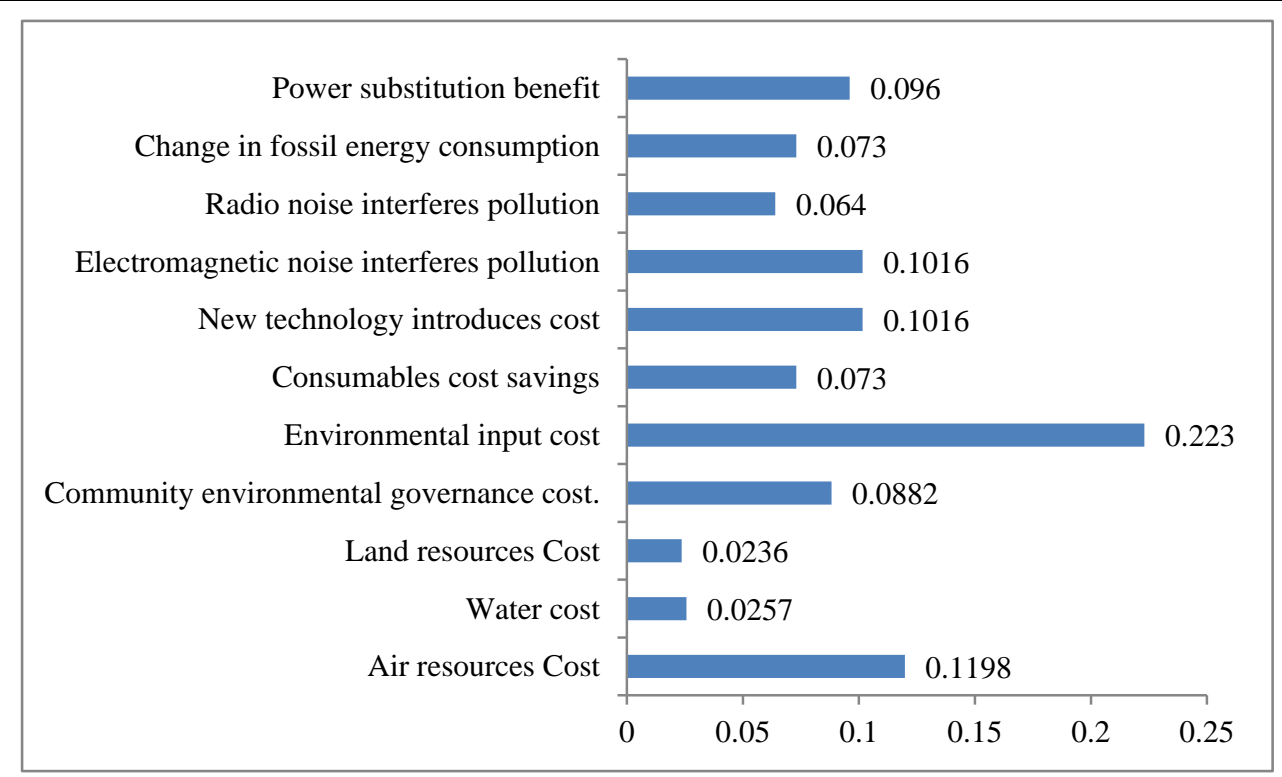

Fig 3. Impact weight of each factor on environmental benefits

\section{References}

[1] Morozow, Michael. Der Georgier: Stalins Weg und Herrschaft / 2. vom Autor durchges. Aufl[M]. Langen-Müller, 2006

[2] Barros, De R P, Henriques, et al. A estabilidade inaceitável: desigualdade e pobreza no Brasil[J]. Ipea Texto Para Discussäo, 2015:53-64.

[3] Attaviriyanupap P, Yokoyama A. Transmission Expansion in the Deregulated Power System Considering Social Welfare and Reliability Criteria[J]. 2016:1-6.

[4] Jing-Ru L I, Zhao B, Shi X F, et al. Analysis Methods of Composite Cost Index for Transmission Projects[J]. Energy Technology \& Economics, 2015.

[5] Pu Wenqing, Liu Hongzhi, Yu Han, et al.Environmental Impact Analysis of Electromagnetic Radiation of Typical Mobile Communication Base Station in Anhui Province[J].Shanxi Architecture,2015, 40(9):216-218. 